九州大学学術情報リポジトリ

Kyushu University Institutional Repository

\title{
Expression of Glycosylated Mucin-like Domain Using Baculovirus Expression System in Silkworm, Bombyx mori
}

Nagata, Yudai

Laboratory of Silkworm Sciences, Division of Genetics and Plant Breeding, Department of Applied Genetics and Pest Management, Graduate School of Bioresource and Bioenvironmental Sciences, Kyushu University

Sakashita, Kosuke

Laboratory of Silkworm Sciences, Division of Genetics and Plant Breeding, Department of Applied Genetics and Pest Management, Faculty of Agriculture, Kyushu University

Imanishi, Shigeo

National Institute of Agrobiological Sciences

Lee, Jae Man

Laboratory of Silkworm Sciences, Division of Genetics and Plant Breeding, Department of Applied Genetics and Pest Management, Faculty of Agriculture, Kyushu University

他

https://doi.org/10.5109/22053

出版情報: 九州大学大学院農学研究院紀要. 57 (1)，pp.83-86，2012-02. Faculty of Agriculture， Kyushu University

バージョン :

権利関係 : 


\title{
Expression of Glycosylated Mucin-like Domain Using Baculovirus Expression System in Silkworm, Bombyx mori
}

\author{
Yudai NAGATA ${ }^{1}$, Kosuke SAKASHITA ${ }^{3}$, Shigeo IMANISHI ${ }^{2}$, \\ Jae Man LEE ${ }^{3}$ and Takahiro KUSAKABE ${ }^{3 *}$
}

\author{
Laboratory of Silkworm Sciences, Division of Genetics and Plant Breeding, Department of Applied Genetics and \\ Pest Management, Faculty of Agriculture, Kyushu University Graduate School 6-10-1 \\ Hakozaki, Higashi-ku, Fukuoka 812-8581, Japan \\ (Received October 27, 2011 and accepted November 9, 2011)
}

\begin{abstract}
Baculovirus expression systems (BES) are widely used for recombinant protein production in lepidopteran cells or larvae. It is known that insect cells have a glycosylation pathway similar to that of mammalian cells. Thus, BES are possible to be used to produce recombinant proteins with higher eukaryotic modifications. In insect cells, the $N$-glycosylation pathway has been well-researched. However, the $O$-glycosylation pathway is poorly understood. In this study, we expressed a partial recombinant HsPRG4 (rPRG4) as a reporter for $O-$ glycosylation and investigated whether BES in silkworm could produce the proteins with mucin-like clustered $O$-glycans. Analysis by SDS-PAGE and glycosidase digestion indicated that rPRG4 had Core 1 and Core $2 O$-glycan chains. These results suggested that BES could produce the protein containing mucin-type $O$-glycosylation in Bombyx mori.
\end{abstract}

Key words: baculovirus expression system, Bombyx mori, O-glycosylation

\section{INTRODUCTION}

Baculovirus expression systems (BES) are valuable and popular tools for the production of recombinant proteins. Because insect cells have a posttranslational modifications similar to those of mammalian cells, such as glycosylation, phosphorylation, and protein folding, BES are used to produce proteins from higher eukaryotes, for example, canine interferons-a, human serine-threonine kinase 11, and human acidic and basic fibroblast growth factors (Liu et al., 2005; Martinez et al., 2005; Gouveia et al., 2007). As regards the glycosylation in insect cells, the $N$-glycosylation pathway has been studied with a view to production of human-like $N$-glycosylated proteins, but there are few reports of $O$-glycosylation. In this study, to investigate whether the mucin-type O-glycosylation occurs in silkworm, Bombyx mori, we performed recombinant protein expression of a mucinlike protein as a target using BES in silkworm.

Mucins are heavily $O-$ glycosylated glycoproteins found in secreted mucous and as transmembrane glycoproteins of the cell surface to serve as a last protective barrier against extracellular environmental factors like low pH or hydrolytic enzymes (Strouss et al., 1992). Mucins have serine and threonine rich domains called variable number of tandem repeat (VNTR) regions. Mucins

${ }^{1}$ Laboratory of Silkworm Sciences, Division of Genetics and Plant Breeding, Department of Applied Genetics and Pest Management, Graduate School of Bioresource and Bioenvironmental Sciences, Kyushu University

National Institute of Agrobiological Sciences, Owashi, Tsukuba, Ibaraki, Japan.

${ }^{3}$ Laboratory of Silkworm Sciences, Division of Genetics and Plant Breeding, Department of Applied Genetics and Pest Management, Faculty of Agriculture, Kyushu University

* Corresponding author (E-mail: kusakabe@agr.kyushu-u.ac.jp) may have hundreds of $O-$ GalNAc glycans attached to serine or threonine residues in the VNTR regions and these abundant $O$-glycan chains may comprise $80 \%$ of the molecule by weight (Lan et al., 1987). Four main $O$-glycan core structures are well known in mammals (Daniel., 2009). The most common $O-$ GalNAc glycan is Gal $\beta$ 1-3GalNAc $\alpha$-Ser/Thr (Fig. 1). It is termed a Core 1 or T-antigen and forms many longer, more complex structures. Another common structure is Core 2, contains a branching $\mathrm{N}$-acetylglucosamine attached to core 1 (Fig. 1). Core 1 and Core 2 O-GalNAc glycans are found in both glycoproteins and mucins from a variety of cells and tissues. Core 3 and Core 4 stuructures (Fig. 1) are found in a few tissues, such as colon (Podolsky., 1985), bronchi (Lamblin., 1984) and salivary glands (Wieruszesk et al., 1987). In insects, Core 1 type mucin has been observed (E Tian et al., 2008), but other type mucins are yet to be detected.

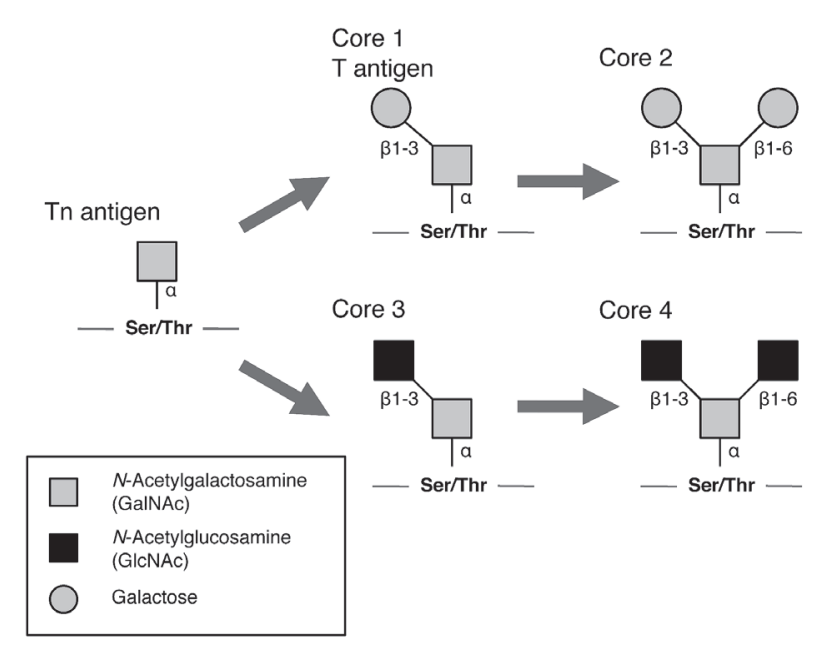

Fig. 1. Biosynthesis of $O-$ GalNAc glycans core structures. 
To assess whether BES in silkworm was capable of producing the proteins with mucin-like clustered $O$-glycans, we constructed the reporter for $O$-glycosylation, which contains the portion of mucin-like repeat domain of PRG4 (proteoglycan 4). PRG4, also known as luricin, has been identified as megakaryocyte stimulating factor and articular cartilage superficial zone protein (Ikegawa et al., 2000). PRG4 contains a large, central, mucin-like repeat domain supporting attachment of $O$-glycan chains (Jay GD, 2004). PRG4 has mainly Core 1 type $O-$ glycans and low amounts of Core 2 type O-glycans (Estrella RP et al., 2010). In this report, we show that BES can produce mucin glycoproteins.

\section{MATERIALS AND METHODS}

\section{Cells and silkworm strain}

The cell line PS140 (a laboratory stock of Dr. Imanishi, National Institute of Agrobiological Sciences) and the d17 silkworm strain (Kawakami et al., 2008) used in this study were provided by the Institute of Genetic Resources, Graduate School of Agriculture, Kyushu University, Japan. The cell line was maintained in IPL-41 medium (Invitrogen, CA, USA) with 10\% fetal bovine serum. The cells were grown at $27^{\circ} \mathrm{C}$. Before cell transfection, the medium was replaced by COSMEDIUM 009 (CosmoBio Co, Tokyo, Japan).

\section{Construction of the Gateway entry clone}

To obtain the partial sequence of HsPRG4, we performed PCR with human liver cDNA template. The PCR reaction was carried out with two primers, PRG4-5NcoI (5'-GGGCCATGGCATGGAAAACACTTCCCATTT-3'), PRG4-3XhoI (5'-CCCCTCGAGGGCTTCTTGGTGGTGGTGGGT-3'). The 50- $\mu \mathrm{L}$ PCR reaction contained $5 \mu \mathrm{L}$ of $10 \times$ KOD buffer, $5 \mu \mathrm{L}$ of $2 \mathrm{mM}$ dNTPs, $1.5 \mu \mathrm{L}$ of each primer $(10 \mu \mathrm{M}), 3 \mu \mathrm{L}$ of $\mathrm{MgSO}_{4}(25 \mathrm{mM}), 1 \mu \mathrm{L}$ of the template, and $1 \mu \mathrm{L}$ of KOD-Plus-Neo DNA polymerase (1.0 U/ $\mu \mathrm{L}$; Toyobo, Osaka, Japan). The amplification profile consisted of a heat denaturation as follows: $94^{\circ} \mathrm{C}$ for $2 \mathrm{~min}$, and then 35 cycles at $94^{\circ} \mathrm{C}$ for $15 \mathrm{sec}, 59^{\circ} \mathrm{C}$ for $30 \mathrm{sec}$, and $68^{\circ} \mathrm{C}$ for $1 \mathrm{~min}$, and then $68^{\circ} \mathrm{C}$ for $5 \mathrm{~min}$. The PCR product was digested with $\mathrm{NcoI}$ and XhoI was cloned into the NcoI / XhoI site of pENTR11 (Invitrogen). pENTR11 was modified to contain polyhistidine $(8 \times \mathrm{His})$ tag. To confirm the inserted sequence, we did sequencing reactions with the ABI BigDye 3.1 Terminator Cycle Sequencing kit (Applied Biosystems, Warrington, UK) with primers, pENTR attL1 (5'-ACTCTTCCTGTTAGTTAGTTACTTAAGCTC-3'), pENTR attL2 (5'-CAATGTAACATCAGAGATTTTGAGACAC-3').

\section{Generation of recombinant baculovirus}

The DNA fragment of HsPRG4 was transposed to pDEST8 (Invitrogen) by means of Gateway LR clonase reaction (Invitrogen). The obtained pDEST8-PRG4His8 transfer vector was transformed into E. coli BmDH10Bac (Motohashi et al., 2005) and transposed to bacmid DNA mediated by Tn7 transposase (Park et al., 2007). After the purification, the recombinant bacmid
DNA were transfected into the B. mori PS140 cells by lipofection method to generate recombinant baculoviruses. Three days after transfection, the culture medium was collected, and the infection was repeated twice for to prepare high-titer virus stock.

\section{Expression and purification of recombinant pro- tein}

Larvae on day 3 of the fifth instar were carefully injected into a hemocoel with the recombinant HsPRG4His8 baculovirus. Four days after infection, larval legs were cut and hemolymph was collected from each larva. The collected hemolymph was diluted with extraction solution (20 mM sodium phosphate, $0.5 \mathrm{M} \mathrm{NaCl}, 10 \mathrm{mM}$ 2-mercaptoethanol, $1 \mathrm{mM}$ phenylmethylsulfonyl fluoride, Complete EDTA-free protease inhibitor cocktail [1 tablet/100 mL] (Roche Applied Science), 20 mM 1-phenyl-2-thiourea ( $\mathrm{pH} 7.0$ ) and centrifuged at 9,500 rpm for $20 \mathrm{~min}$. The supernatant was filtrated through a 0.45 $\mu \mathrm{m}$ membrane filter (Millipore, MA, USA). The recombinant protein was eluted with a linear solvent gradient (5, 20, 100, and $300 \mathrm{mM}$ imidazole). Each fractions were analyzed by sodium dodecyl sulfate-polyacrylamide gel electrophoresis (SDS-PAGE). After electrophoresis, the running gel was stained with Coomassie Brilliant Blue $\mathrm{R}-250$.

\section{Endoglycosidase digestions}

To cleave $O$-glycan chains, purified rPRG4 was incubated in $1 \times$ Glycoprotein Denaturing Buffer (NEB) at $95^{\circ} \mathrm{C}$ for $10 \mathrm{~min}$. The $20-\mu \mathrm{L}$ cleavage reaction contained $2 \mu \mathrm{L}$ of $10 \times \mathrm{G} 7$ Reaction Buffer (NEB), $2 \mu \mathrm{L}$ of $10 \%$ NP40, $2 \mu \mathrm{L}$ of Neuraminidase (NEB), and $1 \mu \mathrm{L}$ of Endo$\alpha-N$-Acetylgalactosaminidase (NEB). The reaction mixture was incubated at $37^{\circ} \mathrm{C}$ for $4 \mathrm{~h}$. The digested product was analyzed by SDS-PAGE.

\section{RESULTS AND DISCUSSION}

\section{Clustered mucin-type $O$-glycans exist on recom- binant PRG4}

To construct the partial recombinant PRG4 (rPRG4), we amplified the DNA fragment from a human liver cDNA library with the PRG4-5NcoI and PRG4-3XhoI primers. We had cloned a partial DNA fragment encoding $N$-terminal signal peptide, somatomedin B-like domains, heparin-binding domain, and a part of mucin-like repeat

\section{Full-length HsPRG4}

\begin{tabular}{l|l|l|l|l|}
\hline SP & SMMB & SMB & HEP & MUCIN-LIKE REPEAT
\end{tabular}

Recombinant PRG4

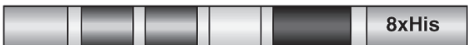

Fig. 2. Structure of recombinant PRG4 constructs. Domains indicated are: SP, signal peptide; SMB, somatomedin B-like; HEP, heparin-binding; HPX, hemopexin-like; 8xHis, C-terminal 8-histidine tag. 
domain into pENTR11 (Fig. 2). To facilitate the protein purification, 8-histidine tag was added to C-terminus.

The recombinant baculovirus was produced by transfecting the bacmid DNA into PS140 cells, and the amplified P3 virus was injected into the hemocoels of silkworm larvae as described under MATERIALS AND METHODS. The hemolymph containing secreted rPRG4 was collected and purified by means of histidine affinity chromatography. The purified rPRG4 was analyzed by separation on SDS-PAGE (Fig. 3). After coomassie brilliant blue staining, the purified rPRG4 was detected at the fractions containing $20 \mathrm{mM}$ and $100 \mathrm{mM}$ imidazole. Although the molecular weight of rPRG4 without modification, calculated from the amino acid sequence, was to be $32.019 \mathrm{kDa}$, a smear band was appeared above $55 \mathrm{kDa}$. This result strongly suggested that clustered $O$-glycan chains exist on mucin-like repeat domain of rPRG4, and
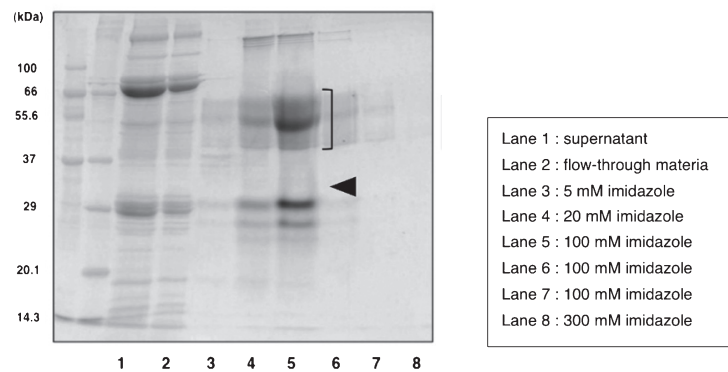

Fig. 3. Purification of rPRG4 detected by SDS-PAGE. Detection of His-tagged rPRG4 fractionated by affinity chromatography: lane 1 , supernatant; lane 2 , flow-through material; lane 3, eluate at $5 \mathrm{mM}$ imidazole; lane 4 , eluate at $20 \mathrm{mM}$ imidazole; lane 5, 6, 7, eluate at $100 \mathrm{mM}$ imidazole; lane 8 , eluate at $300 \mathrm{mM}$ imidazole. The black triangle indicates the position of rPRG4 without modification. The bracket indicates the position of $O$-glycosylated rPRG4.

that BES can produce mucin type $O$-glycan in silkworm.

\section{The BES produced rPRG4 contains Core 2 type $O$-glycosylation}

In order to confirm the addition of $O$-glycan chains, the purified rPRG4 (100 mM imidazole fraction; Fig. 3, lane5) was digested with Neuraminidase and Endo- $\alpha-$ $N$-Acetylgalactosaminidase. Neuraminidase catalyzes the hydrolysis of $\alpha 2-3, \quad \alpha 2-6$, and $\alpha 2-8$ linked $N$-acetyl-neuraminic acid residues, which must be removed before the cleavage the $O$-glycan chains by Endo- $\alpha-N-$ Acetylgalactosaminidase. $\quad$ Endo- $\alpha-N-$ Acetylgalactosaminidase, also known as $O$-glycosidase, catalyzes the removal of Core 1 and Core $30-$ GalNAc glycan from glycoproteins (Koutsioulis et al., 2008), but can not removes Core $2 \mathrm{O}$-glycan. The resulting product was analyzed by separation on SDS-PAGE. The digestion by the two glycosidases decreased the molecular size of rPRG4 markedly (Fig. 4). This result indicates that the rPRG4 has Core 1 and Core 2 type O-GalNAc glycans as well as native PRG4. Taken together, BES can produce the protein containing Core 2 type $O$-glycosylation in Bombyx mori. Interestingly, significant amount of deglycosylation-resistant species were

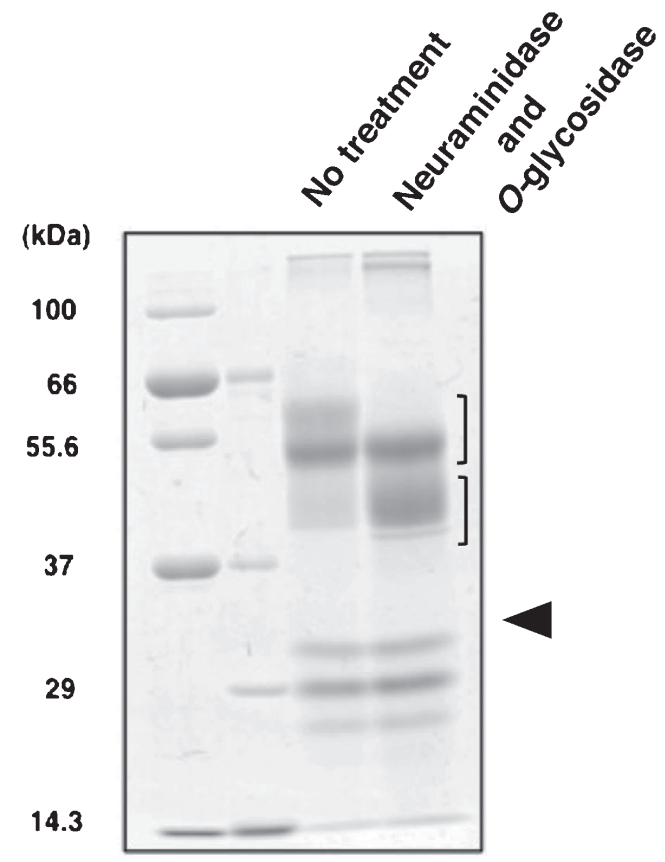

Fig. 4. O-Glycosidase digestion detected by SDS-PAGE. The black triangle indicates the position of rPRG4 without modification. Upper bracket indicates the position of $\mathrm{O}$-glycosidase-resistant rPRG4. Under bracket indicates the position of deglycosylated rPRG4.

observed, suggesting that the rPRG4 produced using BES has a complicated modification other than Core 1 and Core $3 \mathrm{O}-$ GalNAc glycan.

\section{ACKNOWLEDGEMENTS}

This work was supported in part by a grant from the Ministry of Agriculture, Forestry and Fisheries of Japan (Integrated research project for plant, insect and animal using genome technology INSECT-1201), and KAKENHI no. 22248003, 22248004 and 23580077 from the Japan Society for the Promotion of Science.

\section{REFERENCES}

Daniel Ungar 2009 Golgi linked protein glycosylation and associated diseases. Semin Cell Dev Biol., 20: 762-769

E Tian and Kelly G 2009 Recent insights into the biological roles of mucin-type O-glycosylation. Glycoconjugate Journal., 26: $325-334$

Gouveia RM, Morais VA, Peixoto C, Sousa M, Regalla M, Alves PM and Costa J 2007 Production and purification of functional truncated soluble forms of human recombinant L1 cell adhesion glycoprotein from Spodoptera frugiperda Sf9 cells. Protein Expr Purif., 52: 182-193

Ikegawa S, Sano M, Koshizuka Y, and Nakamura Y 2000 Isolation, characterization and mapping of the mouse and human PRG4 (proteoglycan 4) genes. Cytogenet Cell Genet., 90: 291-297

Jay, Gregory D 2004 Lubricin and surfacing of articular joints. Curr Opin Orthop., 15: 335-339

Kawakami N, Lee J. M, Mon H, Kubo Y, Banno Y, Kawaguchi Y, Maenaka K, Park E. Y, Koga K and Kusakabe T 2008 Efficient protein expression in Bombyx mori larvae of the strain d17 highly sensitive to B. mori nucleopolyhedrovirus. Mol. Biotechnol., 40: 180-185

Koutsioulis D, Landry D, and Guthrie EP 2008 Novel endoalpha- $N$-acetylgalactosaminidases with broader substrate spe- 
cificity. Glycobiology., 18: 799-805

Lamblin, G., Boersma, A., Lhermitte, M., Roussel, P., Mutsaers, J. H., van Halbeek, H. and Vliegenthardt, J. F 1984 Further characterization, by combined high-performance liquid chromatography/1H-NMR approach, of the heterogeneity displayed by the neutral carbohydrate chains of human bronchial mucins. Eur. J. Biochem., 143: 227-236

Lan MS, Khorrami A, Kaufman B, and Metzgar RS 1987 Molecular characterization of a mucin-type antigen associated with human pancreatic cancer. The DU-PAN-2 antigen. $J$ Biol Chem., 262: 12863-12870

Liu T, Zhang YZ, and Wu XF 2005 High level expression of functionally active human lactoferrin in silkworm larvae. J Biotechnol., 118: 246-256

Martinez-Torrecuadrada JL, Romero S, Nunez A, Alfonso P, Sanchez-Cespedes M, and Casal JI 2005 An efficient expression system for the production of functionally active human LKB1. J Biotechnol., 115: 23-34

Motohashi T, Shimojima T, Fukagawa T, Maenaka K, and Park E.Y 2005 Efficient large-scale protein production of larvae and pupae of silkworm by Bombyx mori nuclear polyhedrosis virus bacmid system. Biochem. Biophys. Res. Commun., 326 564-569

Park EY, Kageshima A, Kwon MS, and Kato T 2007 Enhanced production of secretory beta $1,3-N$-acetylglucosaminyltransferase 2 fusion protein into hemolymph of Bombyx mori larvae using recombinant BmNPV bacmid integrated signal sequence. $J$ Biotechnol., 129: 681-688

Podolsky, D. K 1985 Oligosaccharide structures of isolated human colonic mucin species. J. Biol. Chem., 260: 15510-15515

Strouss, G. J., and Decker, J 1992 Mucin-Type Glycoproteins. Crit. Rev. Biochem. Mol. Biol., 27: 57-92

Wieruszeski, J.-M., Michalski, J.-C., Montreuil, J., Strecker, G., Peter-Katalinic J., Egge, H., van Halbeek, H., Mutsaers, J. H. G. M., and Vliegenthart, J. F. G 1987 Structure of the monosialyl oligosaccharides derived from salivary gland mucin glycoproteins of the Chinese swiftlet (genus Collocalia) Characterization of novel types of extended core structure, Gal beta(1-3)[GlcNAc beta(1-6)] GalNAc alpha(1$-3) \operatorname{GalNAc}(-\mathrm{ol})$, and of chain termination, [Gal alpha(14)]0-1[Gal beta(1-4)]2GlcNAc beta(1-.). J. Biol. Chem., 262: 6650-6657 